\title{
ANÁLISE DE SÉRIE TEMPORAL PARA AVALIAÇÃO DO PERFIL SOROLÓGICO DA LEPTOSPIROSE BOVINA NO ESTADO DO RIO GRANDE DO SUL DE 1996 A 2006
}

\author{
M. Mesquita ${ }^{1}$, D.C.P. Pellegrini2 ${ }^{2 *}$, J.A. Simões Pires Neto ${ }^{3}$, G.R. Reis ${ }^{1}$, C. Medeiros ${ }^{1}$, L.G. Corbellini ${ }^{4}$
}

${ }^{4}$ Universidade Federal do Rio Grande do Sul, Faculdade de Veterinária, Setor de Medicina Veterinária Preventiva, Laboratório de Epidemiologia Veterinária, Av. Bento Gonçalves, 9090, CEP 91540-000, Porto Alegre, RS, Brasil. E-mail: luis.corbellini@ufrgs.br

\section{RESUMO}

\begin{abstract}
A leptospirose é uma das principais enfermidades responsáveis pela baixa produtividade nos sistemas pecuários bovinos, sendo associada à redução na produção de leite, infertilidade, aborto, natimortalidade, além de aumento nos custos com despesas de assistência veterinária, vacinas e testes laboratoriais. Este estudo teve como objetivo analisar dados laboratoriais de sorologia para leptospirose bovina no Estado do Rio Grande do Sul, durante um período de 1996 a 2006, visando detectar tendências na frequência de reagentes e gerar hipóteses sobre a variação da frequência de soropositivos ao longo deste período. Análises de regressão linear e modelo linear generalizado foram realizadas para detectar tendências e verificar fatores que influenciam na frequência de soropositivos, respectivamente. Durante o período de 11 anos, foram analisadas 18.806 amostras de soro, sendo que 9.385 resultaram positivas (49,9\%). A análise da série temporal por sorovar revelou uma tendência linear crescente estatisticamente significativa na frequência dos seguintes sorovares: Australis, Autumnalis, Bratislava, Copenhageni, Grippotyphosa, Pyrogenes e Tarassovi $(p<0,01)$. Por outro lado, foi observada uma tendência decrescente estatisticamente significativa na frequência dos sorovares Hardjo e Wolffi $(\mathrm{p}<0,01)$ ao longo do período avaliado. Houve uma associação estatisticamente significativa entre índices pluviométricos ( $\mathrm{mm}$ ) e o número de soropositivos para Leptospira spp. ( $\mathrm{p}=0,01, \mathrm{OR}=1,003)$.
\end{abstract}

PALAVRAS-CHAVE: Leptospirose, modelo linear generalizado, bovinos, série temporal.

\begin{abstract}
TIME-SERIES ANALYSIS FOR EVALUATING SEROLOGICAL PATTERN OF BOVINE LEPTOSPIROSIS IN THE STATE OF RIO GRANDE DO SUL FROM 1996 TO 2006. Leptospirosis is an infectious disease that causes losses of productivity in cattle due to reduction of milk production, reproductive disorders and calf mortality, while also increasing costs associated with veterinary care, vaccines and diagnostic tests. The objective of this study was to analyze serological findings for bovine leptospirosis in the State of Rio Grande do Sul, Brazil, in order to detect temporal trends in the frequency of seropositive animals and to generate hypothesis about the fluctuation in seroprevalence along the period from 1996 to 2006. Simple linear regression and generalized linear models were used to analyze trends and verify factors influencing the frequency of seropositive animals, respectively. During 11 years, 18,806 serum samples were analyzed, in which 9,385 were positive (49.9\%). The time-series analysis by serovars revealed a statistically significant increasing trend in the frequency of the following serovars: Australis, Autumnalis, Bratislava, Copenhageni, Grippotyphosa, Pyrogenes and Tarassovi $(p<0.01)$. Conversely, a statistically significant decreasing trend was observed for the serovars Hardjo and Wolffi $(p<0.01)$. There was a significant association between rain precipitation $(\mathrm{mm})$ and the number of samples seropositive for leptospirosis $(\mathrm{p}=0.01, \mathrm{OR}=1,003$ ).
\end{abstract}

KEY WORDS: Leptospirosis, generalized linear model, bovine, time-series.

${ }^{1}$ Fundação Estadual de Pesquisa Agropecuária, Porto Alegre, RS, Brasil.

${ }^{2}$ Universidade do Rio Grande do Sul, Faculdade de Veterinária, Porto Alegre, RS, Brasil.

${ }^{3}$ Fundação Estadual de Pesquisa Agropecuária, Instituto de Pesquisas Veterinária "Desidério Finamor", Laboratório de Leptospirose, Eldorado do Sul, RS, Brasil.

*Doutoranda do Setor de Medicina Veterinária Preventiva, Faculdade de Veterinária, Universidade do Rio Grande do Sul (UFRGS). 


\section{INTRODUÇÃO}

Aleptospiroseéuma zoonose de ampla distribuição geográfica que afeta a maioria dos mamíferos domésticos e silvestres. É causada por uma bactéria do gênero Leptospira, sendoatualmenteclassificadasem 13 espécies patogênicas: L. alexanderi, L. alstonii (genoma espécie 1), L. borgpetersenii, L. inadai, L. interrogans, L. fainei, $L$. kirschneri, L. licerasiae, L. noguchi, L. santarosai, L. terpstrae (genoma espécie 3), L. weilii, L. wolffii, com mais de 260 sorovares descritos(ADLER; MOCTEZUMA, 2010). Asfalhas reprodutivas são importantes pelas perdas econômicas geradas nos sistemas de produção, em várias espécies de produção. Diversos estudos relatam que a leptospirose é uma das principais enfermidades responsáveis pela baixa produtividade nos sistemas pecuários associada à redução na produção de leite, infertilidade, abortamento, natimortalidade, além de aumento nos custos com despesas de assistência veterinária, vacinas e testes laboratoriais (FAINE et al., 1999; VASCONCELLOS et al., 1997; BENNETT et al., 1999). As diferenças observadas nas estimativas de perdas provocadas pela leptospirose são relacionadas com a incerteza quanto à prevalência da doença, pois, muitas vezes, o rebanho está infectado por outras enfermidades que igualmente causam transtornos reprodutivos, como os vírus da diarreia viral bovina (BVDV) e da rinotraqueíte infecciosa bovina (IBR) (GROOMS, 2006; JUNQUEIRA et al., 2006).

Apesar de ser uma enfermidade de distribuição cosmopolita, a sua ocorrência é favorecida pelas condições ambientais vigentes nas regiões de climas tropical e subtropical, onde a elevada temperatura, os períodos do ano com altos índices pluviométricos e o solo neutro ou alcalino favorecem a ocorrência de surtos epidêmicos de caráter sazonal (ELLIS, 1984; ELLIS, 1994; ACHA; SZYFRES, 2001).

Os sorovares mais prevalentes, citados na literatura, em bovinos, são Hardjo, Pomona, Grippotyphosa e Icterohaemorrhagiae, sendo o sorovar Hardjo considerado o mais adaptado à espécie bovina (ADLER ; MocteZuma, 2010; CosTa et al., 1998; Ellis, 1994). Uma vez introduzido em um rebanho, este sorovar estabelece níveis variáveis de infecção, podendo persistir por longos períodos (HaTHAWAY et al., 1986).

Oobjetivo deste estudo foi o de analisar uma série temporal para avaliar tendências da frequência de bovinos soropositivos ao longo de um período de 11 anos, bem como a associação com fatores ambientais de temperatura e índice pluviométrico utilizando dados laboratoriais de exames sorológicos para leptospirose bovina.

\section{MATERIAL E MÉTODOS}

Foi realizado um estudo retrospectivo com base em um levantamento de resultados de exames sorológicos para detecção de anticorpos contra Leptospira spp. em amostras de soro bovino enviadas para o Laboratório de Leptospirose do Instituto de Pesquisas Veterinárias “Desidério Finamor" (IPVDFFEPAGRO Saúde Animal), localizado em Eldorado do Sul, região Metropolitana de Porto Alegre, RS. Foram analisados os exames realizados entre os anos de 1996 a 2006, totalizando 18.806 amostras de soro. As amostras de soro foram provenientes de várias localidades do Estado do Rio Grande do Sul, que foram agrupadas nas seguintes mesorregiões do Estado para o cálculo da frequência de soropositivos por localidade: Centro Ocidental Rio-grandense, Centro Oriental Rio-grandense, Metropolitana de Porto Alegre, Nordeste Rio-grandense, Noroeste Rio-grandense, Sudeste Rio-grandense e Sudoeste Rio-grandense.

A técnica de diagnóstico utilizada, conforme proposto pela Organização Internacional paraSaúde Animal (OIE), Organização Pan-americana deSaúde (OPS) e a Organização Mundial da Saúde (OMS), foi a Soroaglutinação Microscópica (SAM), incluindo 13 sorovares de Leptospira spp., a saber: Australis (Ballico), Autumnalis (Akiyami A), Bratislava (Jez Bratislava), Canicola (Hond utrecht), Copenhageni (M 20), Grippotyphosa (Moska V), Hardjo (Hardjoprajitno), Hebdomadis (Hebdomadis), Icteroahemorrhagiae (RGA), Pyrogenes (Salinem), Pomona (Pomona), Tarassovi (Perepelitsin) e Wolffi (3705). O teste de soroaglutinação microscópica é atualmente o mais utilizado para o diagnóstico de leptospirose. Consiste em fazer reagir partes iguais de diluições seriadas de soros e os antígenos (culturas vivas em meio líquido), que são representantes dos principais sorogrupos que ocorrem na região ou país. O teste foi padronizado por Cole et al. (1973). Os soros foram testados frente aos antígenos de todos os sorovares acima citados. A diluição inicial foi composta de 50 $\mu \mathrm{L}$ de soro diluído em $2,5 \mathrm{~mL}$ de solução tamponada de sorensen distribuídos em placas de ELISA onde eram acrescentados $50 \mu \mathrm{L}$ do antígeno diluído em solução tamponada de sorensen e incubado em estufa escura a $27^{\circ} \mathrm{C}$ por 2 horas para, posteriormente, ser realizada a leitura em microscópio de campo escuro. A triagem foi realizada com o titulo inicial de 1:100 e a titulação final foi feita enquanto houvesse aglutinações na sorologia sendo consideradas, para fins da análise estatística, todas as amostras de soro que apresentassem reação a pelo menos um sorovar com título igual ou superior a 1:100, positiva para leptospirose.

Os dados de temperatura e índices pluviométricos (em milímetros), nos anos de 1996 a 2006, nas mesorregiões do Estado do Rio Grande doSul, foram disponibilizados pelo Laboratório de Meteorologia e Agrometeorologia da Fepagro. Os dados da temperatura e índices pluviométricos foram agrupados 
por mesorregiões, obtendo-se a média mensal ao longo do período.

Para análise da série temporal, os resultados sorológicos dos exames de leptospirose (i.e., total de exames realizados e contagem de soropositivos) foram agrupados por mês, de janeiro de 1996 até dezembro de 2006, totalizando 132 meses. Foi realizada a análise de tendência por meio de modelos de regressão linear simples com o objetivo de descrever a relação entre a variável dependente Y (frequência relativa mensal de soropositivos) e a variável independente $X$ (meses de estudo), de acordo com THRUSField (2007). A análise de regressão também foi feita por sorovar, considerando-se o número mensal de positivos de cada sorovar dividido pelo total mensal de exames positivos para Leptospira spp. (variável dependente $\mathrm{Y}$ ) com relação aos meses de estudo (variável independente $X$ ). A relação entre a variável dependente $Y$ e independente $X$ foi dada pelo modelo de primeira ordem:

$Y=\beta_{0}+\beta_{1} X$, onde $Y$ correspondeà freqüência relativa mensal, $\beta_{0}$ a interceptação de $Y$ e $\beta_{1}$ corresponde ao incremento mensal na frequência relativa de soropositivos onde o valor positivo significa tendência crescente e o valor negativo tendência decrescente. A análise de regressão linear foi realizada no programa STATISTICA versão 6.0 (StatSoft), considerando-se como tendência significativa aquela cujo modelo de regressão estimado obteve um $\mathrm{p} \leq 0,05$.

Um modelo linear generalizado (MLG) foi realizado para análise de associação entre índices pluviométricos (chuvas) e temperatura (variáveis candidatas a explicar o comportamento da série ao longo do tempo) e a contagem de casos positivos agrupados por mês (variável resposta). Onúmero de positivos é uma contagem e, portanto, nem sempre satisfaz as suposições de normalidade. Neste caso, o MLG permite utilizar distribuições de probabilidades da família exponencial (LATORRE; CARDOSO, 2001). O modelo padrão para análise da associação entre dados de contagem ao longo do tempo e variáveis explicativas é baseado na distribuição de Poisson que, em caso de super dispersão, pode ser utilizada a distribuição binomial negativa. $\mathrm{O}$ modelo foi construído utilizando o PROCGENMOD do programa SAS versão 9.1 (SAS Institute) com função de ligação logarítmica e controle de super dispersão por meio da distribuição binomial negativa. Foram utilizadas como variáveis explicativas as médias móveis de três meses da temperatura e índice pluviométrico, bem como a interação entre elas. A média móvel é uma técnica utilizada para suavizar a variação randômica dos pontos e revelar tendências não evidentes (THRUSFIELD, 2007). O número de casos positivos detectados em cada mês de 1996 a 2006 foi ajustado usando o logaritmo do número de exames realizados mensalmente pela criação da variável "offset". O impacto das variáveis explicativas $(X=$ índice pluviométrico e temperatura) sobre a variável resposta $(\mathrm{Y}=$ contagem de soropositivos) foi estimado pelo "odds ratio $(\mathrm{OR})^{\prime \prime}$. O valor de $\mathrm{p} \leq 0,05$ foi considerado como estatisticamente significativo.

\section{RESULTADOS}

Das 18.806 amostras analisadas, 9.385 foram positivas para pelo menos um sorovar $(49,9 \%)$. A frequência de positivos por sorovar está demonstrada na Tabela 1 e o resultado dos exames sorológicos por mesorregiões do Rio Grande do Sul na Tabela 2. Durante o período avaliado, a frequências de soropositivos mensais variaram de $8 \%$ a $95 \%$.

Tabela 1 - Frequência relativa por sorovar nas 9385 amostras positivas para Leptospira spp. de um total 18.806 soros bovinos testados no período de 1996 a 2006 no Estado do Rio Grande do Sul.

\begin{tabular}{lcc}
\hline Sorovares & Positivos & $\begin{array}{c}\text { Frequência } \\
\text { relativa }(\%)^{*}\end{array}$ \\
\hline Canicola & 472 & $5,03 \%$ \\
Pyrogenes & 602 & $6,41 \%$ \\
Tarassovi & 771 & $8,22 \%$ \\
Autumnalis & 941 & $10,03 \%$ \\
Grippotyphosa & 949 & $10,11 \%$ \\
Icterohaemorragiae & 975 & $10,39 \%$ \\
Australis & 1253 & $13,35 \%$ \\
Copenhageni & 1372 & $14,62 \%$ \\
Hebdomadis & 1513 & $16,12 \%$ \\
Pomona & 1534 & $16,35 \%$ \\
Bratislava & 1885 & $20,09 \%$ \\
Wolffi & 2739 & $29,18 \%$ \\
Hardjo & 4405 & $46,94 \%$ \\
\hline
\end{tabular}

*Frequência relativa obtida pela divisão do número de positivos de cada sorovar pelo total de positivos para Leptospira spp. (9385).

A proporção de soropositivos mensal apresentou uma tendência crescente estatisticamente significativa ( $p<0,001$ ), ao longo dos 132 meses no período de 1996 a 2006. Conforme a análise de regressão linear houve, a cada mês, um incremento de 0,36\% na frequência relativa de soropositivos para Leptospira spp. no período estudado. Na Tabela 3 estão apresentados os resultados da análise das tendências de soropositivos para Leptospira spp. e por sorovar. A análise por sorovar revelou uma tendência linear 
crescente estatisticamente significativa na frequência dos seguintes sorovares: Australis, Autumnalis, Bratislava, Copenhageni, Grippotyphosa, Pyrogenes e Tarassovi $(p<0,01)$. Por outro lado, foi observada uma tendência decrescente estatisticamente significativa na frequência dos sorovares Hardjo e Wolffi $(p<0,01)$ ao longo do período avaliado. A frequência dos demais sorovares (Canicola, Hebdomadis, Icteroahemorrhagiae e Pomona) mostra que estes se comportaram de forma estável durante o período $(\mathrm{p}>0,1)$.

Tabela 2 - Freqüência relativa de soropositivos para Leptospira spp. por mesorregiões do Estado do Rio Grande do Sul em 18.806 amostras de soro bovino avaliadas no período de 1996 a 2006.

\begin{tabular}{lcc}
\hline Mesorregião & $\begin{array}{c}\text { Amostras por } \\
\text { mesorregião } \\
(\%)\end{array}$ & $\begin{array}{c}\text { Soropositivos } \\
\text { por } \\
\text { mesorregião }(\%)\end{array}$ \\
\hline CentroOcidental & $453(2,4 \%)$ & $204(45,0 \%)$ \\
Sudeste & $603(3,2 \%)$ & $299(49,6 \%)$ \\
Centro Oriental & $1354(7,1 \%)$ & $688(50,8 \%)$ \\
Nordeste & $2197(11,7 \%)$ & $850(38,7 \%)$ \\
Sudoeste & $3853(20,5 \%)$ & $1872(48,6 \%)$ \\
Noroeste & $4161(22,1 \%)$ & $2035(48,9 \%)$ \\
Metropolitana & $6185(32,8 \%)$ & $3437(55,6 \%)$ \\
\hline Total & $18806(100 \%)$ & $9385(49,9 \%)$ \\
\hline
\end{tabular}

O modelo utilizando a distribuição de Poisson apresentou super dispersão que foi ajustada utilizando a distribuição binomial negativa. Observou-se associação estatisticamente significativa entre a contagem de soropositivos e a média móvel das chuvas no MLG, ocorrendo um incremento da contagem de soropositivos de acordo com o aumento do índice pluviométrico ( $p=0,01 ; O R=1,003)$. Não foi encontrada associação entre a contagem de soropositivose a média móvel da temperatura $(p=0,75)$, bem como a interação entre chuva e temperatura $(p=0,053)$. O resultado do modelo está descrito na Tabela 4. A curva alisada do número de soropositivos e chuvas ao longo dos 132 meses está demonstrada na Figura 1.

\section{DISCUSSÃO}

Das 18.806 amostras recebidas no laboratório de leptospirose do IPVDF durante 11 anos, 9.385 foram positivas $(49.9 \%)$, variando de $8 \%$ a $95 \%$ ao longo do período. Este dado indica uma endemicidade da infecção no rebanho bovino no Rio Grande do Sul, provavelmente pela permanência de animais portadores assintomáticos que eliminam o microorganismo pela urina de forma contínua ou intermitente no rebanho por períodos variáveis e pela existência de inúmeros hospedeiros reservatórios de leptospira, tanto domésticos quanto silvestres (ELLIS, 1994).

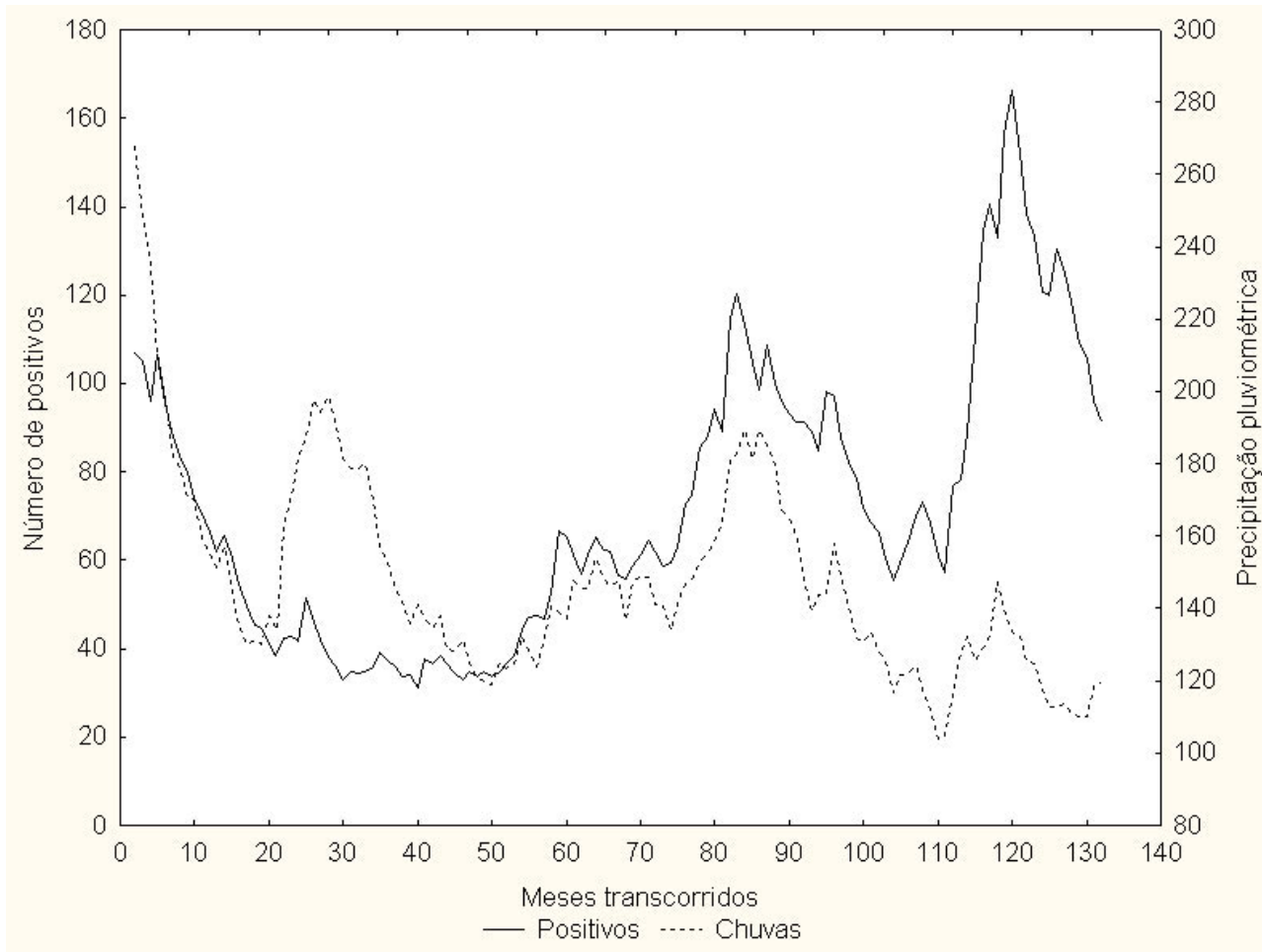

Fig. 1 - Dados alisados do número de exames positivos para Leptospira spp. em bovinos e do índice pluviométrico ao longo dos 132 meses para Estado do Rio Grande do Sul, 1996 a 2006. 
O sorovar Hardjo foi o mais frequente no presente estudo, com uma frequência de $46,94 \%$ nas amostras analisadas, seguida pelas sorovares Wolffi $(29,18 \%)$, Bratislava (20,09\%) e Pomona (16,35\%). O predomínio da Hardjo está de acordo com vários estudos desenvolvidos em diversas regiões do Brasil: no Rio Grande do Sul (Brod et al., 1995), em Minas Gerais (ARAújo et al., 2005), na Paraíba (Mineiro et al., 2007), no Amazonas (Homem et al., 2001) e em São Paulo (JunQueira et al., 2006). FAVERo et al. (2001) encontraram o sorovar Hardjo como a mais prevalente no soro de 31.325 bovinos amostrados em 21 estados brasileiros. Segundo Grooms(2006), os casos mais comuns de leptospirose entre bovinos são causados pela sorovar Hardjo, sendo o bovino o principal reservatório deste sorovar. No entanto, LANGONI et al. (2000) encontrou no Estado de São Paulo o sorovar Wolffi como mais prevalente seguido pela Hardjo.

A água e temperatura exercem um papel primordial no ciclo da leptospirose, pois as leptospiras têm uma sobrevida longa em solos úmidos e alcalinos e temperaturas amenas (ElLIS , 1994). As flutuações regulares e periódicas da leptospirose a caracterizam como uma enfermidade cíclica. Esta flutuação tornase sazonal em regiões onde o período de chuvas é bem definido. No Estado do Rio Grande do Sul, entretanto, a ocorrência de chuvas é esparsamente distribuída ao longo do ano, sendo assim, a ocorrência de soropositivos nesta região acompanhou as flutuações das chuvas, sem evidências claras de sazonalidade (Fig. 1). Estudos de leptospirose em seres humanos em regiões do Brasil, onde as chuvas têm caráter sazonal, demonstram uma tendência cíclica sazonal de casos clínicos da doença (PelleGRINI, 2003). Entretanto, avaliações por um período maior e análise do componente sazonal da série são necessárias em futuras investigações.
Com relação às mesorregiões do Estado, notase (Tabela 2) que a maior frequência de amostras enviadas foram provenientes das mesorregiões metropolitana $(32,8 \%)$, noroeste $(22,1 \%)$ e sudoeste (20,5\%). As mesorregiões do sudeste, por exemplo, enviaram aolaboratório 603 amostras $(3,2 \%)$ ao longo dos 11 anos. Porém, a frequência de positivos entre as mesorregiões não demonstrou grande variabilidade, pois se situou entre 38,7\% (mesorregião nordeste) a $55,6 \%$ (mesorregião metropolitana). Istoé um indicativo de que a infecção está amplamente difundida na população bovina do Estado do Rio Grande do Sul, porém os indicadores devem ser avaliados com cuidado haja vista tratar-se de amostras delaboratórioe, portanto, com uma representatividade prejudicada.

A análise da série temporal por sorovar (Tabela 3) revelou tendências lineares crescentes (Australis, Autumnalis, Bratislava, Copenhageni, Grippotyphosa, Pyrogenes e Tarassovi), decrescentes (Hardjo e Wolffi) e ainda sem alteração significativa (Canicola, Hebdomadis, Icteroahemorrhagiae e Pomona) para as sorovares testadas. Este fato poder ser explicado, parcialmente, pelo uso mais frequente, nos últimos anos, de programas de vacinação contra leptospirose. As vacinas comerciais não contemplam todos os sorovares prevalentes, mas, como o sorovar Hardjo tem sido amplamente divulgado como o mais frequente em bovinos, este sempre comparece nas vacinas, e mostrou uma redução significativa na análise da série temporal ao longo dos 132 meses. Este quadro pode provocar um viés em favor do hospedeiro, o que resulta em tendência decrescente ao longo de um período (THURSFIELD, 2007). O contrário pode ter ocorrido com os outros sorovares, ocorrendo um viés em favor ao agente, causando uma tendência crescente dos casos ao longo de um período de tempo.

Tabela 3 - Resultados da análise de tendência da frequência relativa de Leptospira spp. ao longo de 132 meses para o Estado do Rio Grande do Sul, 1996 a 2006.

\begin{tabular}{lccccc}
\hline Sorovar & Modelo & $\mathrm{r}^{*}$ & $\mathrm{r}^{2 * *}$ & Tendência & $\mathrm{P}$ \\
\hline Leptospira spp. & $\mathrm{y}=0,29+0,0036 \mathrm{x}$ & 0,58 & 0,34 & Crescente & $<0,001$ \\
Australis & $\mathrm{y}=0,03+0,0011 \mathrm{x}$ & 0,39 & 0,15 & Crescente & $<0,001$ \\
Autumnalis & $\mathrm{y}=0,05+0,0017 \mathrm{x}$ & 0,54 & 0,29 & Crescente & $<0,001$ \\
Bratislava & $\mathrm{y}=0,04+0,0018 \mathrm{x}$ & 0,49 & 0,24 & Crescente & $<0,001$ \\
Canicola & $\mathrm{y}=0,04+0,0000 \mathrm{x}$ & 0,03 & 0,00 & Estável & 0,680 \\
Copenhageni & $\mathrm{y}=0,11+0,0031 \mathrm{x}$ & 0,55 & 0,31 & Crescente & $<0,001$ \\
Grippotyphosa & $\mathrm{y}=0,02+0,0007 \mathrm{x}$ & 0,35 & 0,12 & Crescente & $<0,001$ \\
Hardjo & $\mathrm{y}=0,74-0,0036 \mathrm{x}$ & 0,53 & 0,28 & Decrescente & $<0,001$ \\
Hebdomadis & $\mathrm{y}=0,14+0,0000 \mathrm{x}$ & 0,01 & 0,00 & Estável & 0,844 \\
Icteroahemorrhagiae & $\mathrm{y}=0,08+0,0003 \mathrm{x}$ & 0,10 & 0,00 & Estável & 0,225 \\
Pomona & $\mathrm{y}=0,17-0,0003 \mathrm{x}$ & 0,09 & 0,00 & Estável & 0,263 \\
Pyrogenes & $\mathrm{y}=0,03+0,0004 \mathrm{x}$ & 0,19 & 0,03 & Crescente & 0,002 \\
Tarassovi & $\mathrm{y}=0,03+0,0006 \mathrm{x}$ & 0,24 & 0,05 & Crescente & 0,005 \\
Wolffi & $\mathrm{y}=0,37-0,0011 \mathrm{x}$ & 0,22 & 0,05 & Decrescente & 0,008 \\
\hline *riscre
\end{tabular}

${ }^{*} \mathrm{r}=$ coeficiente de correlação; ${ }^{* *} \mathrm{r}^{2}=$ coeficiente de determinação. 
Tabela 4 - Resultado do modelo linear generalizado para a análise de associação entre contagem de positivos para Leptospira spp. e índice pluviométrico (chuvas) e temperatura.

\begin{tabular}{lcc}
\hline Variáveis Explicativas & $\mathrm{OR}^{*}$ & $\mathrm{P}$ \\
\hline Chuvas - média móvel 3 meses & 1,003 & 0,011 \\
Temperatura - média móvel 3 meses & 0,994 & 0,752 \\
Interação chuva e temperatura & 1,000 & 0,053 \\
\hline * "Odds ratio"
\end{tabular}

O modelo linear generalizado evidenciou uma associação entre a contagem de positivos e o índice pluviométrico $(\mathrm{P}=0,011)$. Observou-se neste estudo que, em vários momentos, ao longo dos 132 meses, os picos de soropositividade para leptospirose e índice pluviométrico coincidem (Fig. 1). Provavelmente, períodos de maior precipitação, aliados a outros fatores, propiciam condições favoráveis para a sobrevivência do micro-organismo fora do hospedeiro, resultando em maior período de exposição. Segundo ELLIS (1994), outros fatores relevantes, como pH neutro a levemente alcalino, aumentam ainda mais as chances de sobrevivência do agente por longos períodos. Mineiro et al. (2007) avaliando as prevalências mensais, segundo as estações do ano, observaram um aumento de soropositividade no período chuvoso. BROD et al. (1995), em um levantamento de 4 anos de estudo, não observaram coincidência entre picos de índice pluviométrico e prevalência de leptospirose e MiLLER et al. (1991) encontraram relação entre temperatura média e frequência de isolamento de leptospira nos Estados Unidos.

A tendência crescente na frequência de leptospirose observada neste estudo pode ter ocorrido pelos seguintes fatores: a falta de diagnóstico dos portadores ea persistência desses animais no rebanho e o aumento na frequência de sorovares não reconhecidas como de importância para a pecuária bovina e que não estão presentes nas vacinas comerciais (Copenhageni, Australis, Autumnalis, Pyrogenes e Tarassovi). Da mesma forma, a tendência decrescente (Hardjo e Wolffi) ou estabilidade na frequência de alguns sorovares (Canicola, Hebdomadis, Icteroahemorrhagiae e Pomona) poderia estar associada ao uso de vacinas que contêm estes sorovares. LOBO et al. (2004), em um levantamento sorológico para leptospirose em animais domésticos criados em locais onde ocorreram notificações da doença em humanos, observaram que os sorovares mais frequentes nas amostras foram aqueles que normalmente não se encontram nas vacinas comercializadas para animais no país.

\section{CONCLUSÕES}

Por meio das análises realizadas em soros bovinos ( $n=18.806)$, enviadas ao laboratório da Fundação
Estadual de Pesquisa Agropecuária, no período de 11 anos, conclui-se que houve uma associação estatisticamente significativa entre índices pluviométricos (chuvas) e o número de soropositivos para Leptospira spp. $(p=0,01)$. A análise de regressão simples por sorovar revelou uma tendência linear estatisticamente significativa crescente (Australis, Autumnalis, Bratislava, Copenhageni, Grippotyphosa, Pyrogenes e Tarassovi) e decrescente (Hardjo e Wolffi), além da estabilidade da frequência de soropositivos para alguns sorovares (Canicola, Hebdomadis, Icteroahemorrhagiae e Pomona). É necessário um cuidado ao generalizar os resultados para a população bovina do Estado do Rio Grande do Sul, haja vista a não aleatoriedade das amostras estudas, porém, eles são um importante indicativo da influência das chuvas na ocorrência de leptospirose e da endemicidade da infecção nos bovinos da referida região.

\section{AGRADECIMENTOS}

Ao Conselho Nacional de Desenvolvimento Científico e Tecnológico, pelo apoio financeiro (Processo 570365/2008 - 2).

\section{REFERÊNCIAS}

ACHA, P.N.; SZYFRES, B. Zoonosis y Enfermidades Transmisibles Comunes al Hombre y a los Animales. Vol I. Bacteriosis y Micosis. Washington: OPAS, 2001.

ADLER, B.; MOCTEZUMA, A.P. Leptospira and leptospirosis. eterinary microbiology, v.140, p.287-296, 2010.

ARAÚJO, V.E.M.; MOREIRA, E.C.; NAVEDA, L.A.B.; SILVA, J.A; CONTRERAS, R.L. Freqüência de aglutininas anti-Leptospira interrogans em soros sangüíneos de bovinos, em Minas Gerais, de 1980 a 2002. Arquivo Brasileiro de Medicina Veterináriae Zootecnia, v.57, n.4, p.430-435, 2005.

BENNETT, R.; CHRISTIANSEN, K.; CLIFTON-HADLEY, R.S. Estimating the costs associated with endemic diseases of dairy cattle. Journal of Dairy Research, v.66 p.455-459, 1999.

BROD, C.S.; MARTINS, L.R.I.; NUSSBAUM, J.R.; FEHL-BERG, M.F.B.; FURTADO, L.R.I.; ROSADO, 
R.L.I. Leptospirose bovina na região sul do Estado do Rio Grande do Sul. A Hora Veterinária, v.14, n.84, mar/ abr., 1995.

COSTA, M.C.R; MOREIRA, E.C; LEITE, R.C.; MARTINS, N.R.S. Avaliação da imunidade cruzada entre Leptospira hardjo e L. wolfi. Arquivo Brasileiro de Medicina Veterinária e Zootecnia, v.50, n.1, p.11-17, 1998.

COLE, J.R.; SULZER, C.R.; PURSSEL, A.R. Improved microtechnique for the leptospial microscopie agglitination test. Applied Microbiology, v.25, n.6, p.976980, 1973.

ELLIS, W.A. Bovine Leptospirosis in the tropics: prevalence, pathogenesis and control. Preventive Veterinary Medicine, v.2, p.411-421, 1984.

ELLIS, W.A. Leptospirosis as a cause of reproductive failure. Veterinary Clinics of North America, v.10, n.3, p.463-478, 1994.

FAINE, S.; ADLER, B.; BOLIN, C.; PEROLAT, P. Leptospira and leptospirosis. 3.ed. Melbourne: MediSci, 1999. 272p.

FAVERO, M.; PINHEIRO, S.R.; VASCONCELLOS, S.A.; MORAIS Z.M.; FERREIRA F.; FERREIRA NETO J.S. Leptospirose bovina - variantes sorológicas predominantes em colheitas efetuadas no período de 1984 a 1997 em rebanhos de 21estados do Brasil. Arquivos do Instituto Biológico, São Paulo, v.68, n.2, p.29-35, 2001.

GROOMS, D.L. Reproductive losses caused by bovine viral diarrhea virus and leptospirosis. Theriogenology, v.66 p.624-628, 2006.

HANSON, L.E. Immunology of bacterial diseases, with special reference to leptospirosis. Journal of the American Veterinary Medical Assocociation, v.170, n.9, p.991-994, 1997.

HATHAWAY, S.C; LITTLE, T.W.; PRITCHARD, D.G. Problems associated with the serological diagnosis of Leptospira interrogans serovar hardjo infection in bovine populations. Veterinary Record, v.119, p. 84-86, 1986.

HOMEM, V.S.F.; HEINEMANN, M.B.; MORAES, Z.M.; VASCONCELLOS, S.A.; FERREIRA, F.; FERREIRA, NETO, J.S. Estudo epidemiológico da leptospirose bovina e humana na Amazônia oriental brasileira. Revista da Sociedade Brasileira de Medicina Tropical, v.34, p.173-180, 2001.

JUNQUEIRA, J.R.C.; FREITAS, J.C.; ALFIERI, A.F.; ALFIEIRI, A.A. Avaliação do desempenho reprodutivo de um rebanho bovino de corte naturalmente infectado com o BoHV-1, BVDV e Leptospira hardjo. Semina. Ciências Agrárias, v.27, n.3, 2006.
LANGONI, H.; MEIRELES, L.R.; GOTTSCHALK, S.; CABRAL, K.G.; SILVA, A.V. Perfil sorológico da leptospirose bovina em regiões do Estado de São Paulo. Arquivos do Instituto Biológico, São Paulo, v.67, n.1, p.37-41, 2000.

LATORRE, M.R.D.O.; CARDOSO, M.R.A. Análise de séries temporais em epidemiologia: uma introdução sobre os aspectos metodológicos. Revista Brasileira de Epidemiologia, v.4, n.3, p.145-152, 2001.

LOBO, E.A.; TAUTZ, S.M.; CHARLIER, C.F.; CONCEIÇÃO, A.; SIMÕES PIRES NETO, J.A. Estudo comparativo do padrão sorológico de animais domésticos potencialmente transmissores de leptospirose no município de Santa Cruz do Sul, RS, Brasil, entre os anos 2002 e 2003. Caderno de Pesquisa. Série Biológica, v.16, p.47-64, 2004.

MILLER, D.A.; WILSON, M.A.; BERAN, G.W. Survey to estimative prevalence of Leptospira interrogans infection in mature catlle in the United States. American Journal of Veterinary Research, v.52, p.1761-1768, 1991.

MINEIRO, A.L.B.B.; BEZERRA, E.A.; VASCONCELLOS, S.A.; COSTA, F.A.L.; MACEDO, N.A. Infecção por leptospira em bovinos e sua associação com transtornos reprodutivos e condições climáticas. Arquivo Brasileiro de Medicina Veterinária e Zootecnia, v.59, n.5, p.1103-1109, 2007.

PELLEGRINI, D.C.P. Análise espaço-temporal da lepstospirose no município do Rio de Janeiro (1995-1999). 2003. 59f. Dissertação (Mestrado em Saúde Pública) - Fundação Oswaldo Cruz (FIOCRUZ), Escola Nacional de Saúde Pública, Rio de Janeiro, 2003.

SALDANHA, G.B.; CAVAZINI, N.C.; SILVA, A.S.; FERNANDES, M.B.; BADKE, M.R.T.; PIVETTA, C.G. Ciência Rural, v.37, n.4, p.1182-1184, 2007

THRUSFIELD, M. Veterinary epidemiology. London: Butterworths, 2007. 610p.

VASCONCELLOS S.A.; BARBARINI JÚNIOR O.; UMEHARA O.; ORAIS Z.M.; CORTEZ A.; PINHEIRO S.R.; FERREIRA F.; FAVERO A.C.M.; FERREIRA NETO J.S. Leptospirose bovina. Níveis de ocorrência e sorotipos predominantes em rebanhos dos Estados de Minas Gerais, São Paulo, Rio de Janeiro, Paraná, Rio Grande do Sul e Mato Grosso do Sul. Período de janeiro a abril de 1997. Arquivos do Instituto Biológico, São Paulo, v.64, n.2, p.7-15, 1997.

Recebido em 28/11/08

Aceito em 15/6/10 